\title{
Hepatitis C Virus Infection: Newer Paradigms
}

\author{
Srikant Behera ${ }^{1}$, Amir Hasan Syed ${ }^{2}$, Quaiser Saif ${ }^{3}$, Khan Ruhi ${ }^{4}$ \\ ${ }^{1}$ Junior Resident, ${ }^{2}$ Assistant Professor, ${ }^{3}$ Assistant Professor ${ }^{3}$, Assistant Professor ${ }^{4}$ \\ Department of Medicine, JNMC, AMU
}

\begin{abstract}
Infections caused by Hepatitis C Virus (HCV) lead to persistent infection in most of the times and may cause fibrosis of liver, cirrhosis and hepatocellular carcinoma. At present, there is no vaccine available for prevention or treatment of $i$. With the development of newer and effective anti viral drugs, most of the infections are curable. But a proportion of infections may progress to cirrhosis of liver /or hepatocelllar carcinoma in spite of being cured from the infection. So, early diagnosis of HCV infections and treatment with effective antiviral drugs is required for prevention of end stage liver disease.
\end{abstract}

Keywords: hepatitis $C$, transmission, cirrhosis, treatment, prevention

\section{Introduction}

Hepatitis C virus (HCV) causes hepatitis which, like other forms of viral hepatitis leads to inflammation of the liver and damage the liver cells. Itis a major cause of morbidity and mortality throughout the world. More than 185million people are infected with HCV worldwide, out of which 350,000 die each year. [1]Prevalence of anti-HCV in general population of India is approximately $1 \%$ of which $80 \%$ have detectable HCV RNA.[2] HCV is a 40-60nm enveloped single stranded positive sense RNA virus with 9400 base pair genome which was identified as the cause of non-A non-B hepatitis in 1989. It belongs to genus Hepacivirus in family Flaviviradae. There are 6 genotypes (1-6); genotype 3 is most common in India followed by genotype 1 . The treatment modality for hepatitis $\mathrm{C}$ virus (HCV) infection has evolved substantially with the introduction of highly effective $\mathrm{HCV}$ protease inhibitors. These new compounds can cure more than $90 \%$ cases of $\mathrm{HCV}$ infections.

Natural History: HCV infections can present as an acute hepatitis, but more commonly leads to chronic hepatitis and chronic liver disease. Acute HCV hepatitis usually is asymptomatic. Symptomatic acute HCV infections usually have a mild clinical course and rarely lead to hepatic failure. But as spontaneous viral clearance is very low, about $60-80 \%$ cases of acute infections develop chronic infection; $20-30 \%$ of chronic infections develop cirrhosis and among those with cirrhosis, $1-4 \%$ develops hepatocellular carcinoma (HCC) per year. [3]It differs from other chronic viral infections in that it can be cured by treatment. There are different strains of the hepatitis $C$ virus which influence the way the virus replicates in the body, the course of the disease and the response of the disease to treatment. There is currently no vaccine against hepatitis $\mathrm{C}$.

Transmission: The hepatitis $\mathrm{C}$ virus is usually transmitted through close contact with the blood of an infected person but in many cases, it is not possible to trace the source of the infection. Blood transfusions have been a significant source of hepatitis C infection before 1992.Transmission can also occur through intravenous drug use, tattooing, sexual intercourse. There is also risk of transmission to a baby during pregnancy or childbirth.

Symptoms: Acute hepatitis $\mathrm{C}$ symptoms Only a small proportion of people infected with the hepatitis $\mathrm{C}$ virus develop acute hepatitis. Symptoms include loss of appetite, nausea, tiredness, fever, abdominal pain and jaundice. It is usually a mild illness from which most people recover within four to eight weeks. Some people infected with the hepatitis $\mathrm{C}$ virus will rid their bodies of it completely but majority of the cases the virus remains in the body. These people are referred to as chronic carriers. Because most of the people infected with the hepatitis $\mathrm{C}$ virus do not develop the acute illness, they are not aware that they are chronic carriers. However, theytransmit the virus to other people.

\section{Chronic hepatitis C symptoms}

Chronic carriers of hepatitis $\mathrm{C}$ are at risk of chronic liver disease, which causes progressive damage to the liver. Symptoms of chronic liver disease may not manifest for many years. Early symptoms include mild fatigue, a feeling of being unwell, and alcohol intolerance. Serious complications of chronic liver disease, such as cirrhosis may take more than 20 years to develop after infection with the virus. People with cirrhosis may also develop liver failure or hepatocellular carcinoma. 


\section{Whom to test for HCV:}

Identification of those with active HCV infection is the most crucial step in treatment and prevention of $\mathrm{HCV}$. HCV testing is recommended in select populations and it is based on proven benefits of care and treatment in reducing the risk of hepatocellular carcinoma and all-cause mortality.

1. Persons born between 1945 and 1965

2.Risk behaviours:Injection-drug use (current or ever); Intranasal illicit drug use

3.Risk exposures:Long-term haemodialysis (ever);getting a tattoo in an unregulated setting;healthcare, emergency medical, and public safety workers after needle sticks, sharps, ormucosal exposures to HCV-infected blood;Children born to $\mathrm{HCV}$-infected women; Prior recipients of transfusions or organ transplants, including persons who were notified that they received blood from a donor who later tested positive for HCVinfection,received a transfusion of blood or blood components, or underwent an organ transplantbefore July 1992, received clotting factor concentrates produced before 1987

4. Other medical conditions: HIV infection,unexplained chronic liver disease and chronic hepatitis including elevated alanineaminotransferase.

\section{Recommendations for HCV testing:}

A) An anti-HCV test is recommended for $\mathrm{HCV}$ testing and if the result is positive, current infection should be confirmed by a sensitive RNA test.

B) Among persons with a negative anti-HCV test who are suspected of having liver disease, testing for $\mathrm{HCV}$ RNA or follow-up testing for HCV antibody is recommended if exposure to HCV occurred within the past 6 months; testing for HCV RNA can also be considered in persons who are immunocompromised.

C) Prior to initiation of HCV therapy, quantitative HCV RNA testing is necessary to document the baseline level of viremia, because the degree of initial viral decline is a crucial marker of the effectiveness of treatment.

D) Among persons suspected of re-infection after previous spontaneous or treatment-related viral clearance, initial HCV-RNA testing is recommended because an anti-HCV test is expected to be positive.

\section{Diagnosis}

Hepatitis $\mathrm{C}$ may be suspected in a back ground of vague symptoms of being unwell with abnormal liver function. A blood test for hepatitis $\mathrm{C}$ antibodies determines whether a patient has been exposed to the virus and further blood test to confirm the presence of the actual virus in the blood. Quantitative HCV RNA testing is recommended prior to the initiation of antiviral therapy to document the baseline level of viremia (baseline viral load). Testing for HCV genotype is recommended to guide selection of the most appropriate antiviral regimen. If found to have positive results for anti-HCV test and negative results for HCV RNA by PCR, persons should be informed that they do not have evidence of current (active) HCV). Persons with current (active) HCV infection should receive education and interventions aimed at reducing progression of liver disease and preventing HCV transmission toothers. It is recommended to Abstinence from alcohol, evaluation for other conditions which accelerate liver fibrosis, including HBV and HIV infections, Vaccination against hepatitis A and hepatitis B, evaluation for advanced fibrosis using liver biopsy, imaging, or non-invasivemarkers in all persons with HCV.

\section{CDC Recommended Testing Sequence for Identifying Current HCV Infection}

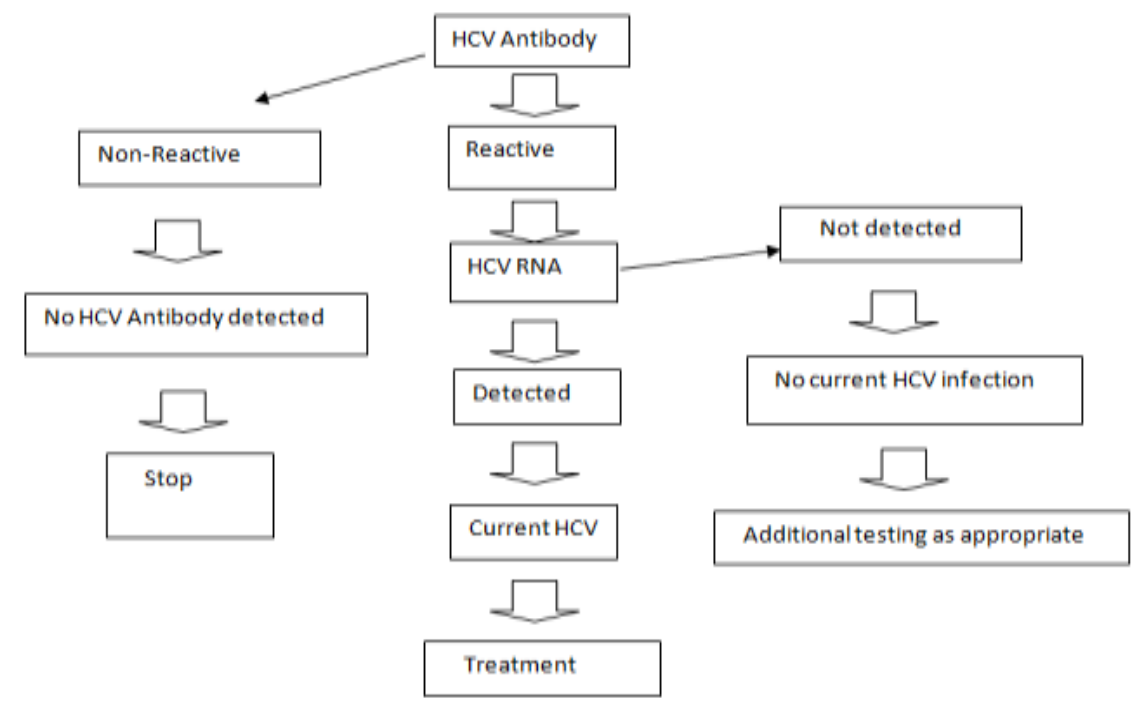


Factors Associated With Accelerated Fibrosis Progression:

Non-modifiable factors like Fibrosis stage, Inflammation grade, older age at time of infection, male sex and Organ transplant; Modifiable factors like Alcohol consumption, Non-alcoholic fatty liver disease, Obesity and Insulin resistance and viral factors like $\mathrm{HCV}$ genotype 3 and Co-infection with hepatitis B virus.

Treatment: Goals of treatment is sustained long term serum HCV RNA negativity to prevent progressive liver damage, development of cirrhosis, decompensation and HCC. HCV can be completely eradicated from body with therapy. The proximate goal of HCV therapy is SVR (virologic cure), defined as the continued absence of detectable HCV RNA at least 12 weeks after completion of therapy. SVR is a marker for cure of HCV infection. Evaluation for advanced fibrosis using liver biopsy, imaging, and/or noninvasive markers is recommended for all persons with $\mathrm{HCV}$ infection, to facilitate an appropriate decision regarding HCV treatment strategy and to determine the need for initiating additional measures for the management of cirrhosis (eg, hepatocellular carcinoma screening). Ongoing assessment of liver disease is recommended for persons in whom therapy is deferred.

\section{When and in whom to initiateTreatment:}

Treatment is recommended for all patients with chronic HCV infection, except those with short life expectancies that cannot be remediated by treating HCV, by transplantation, or by other directed therapy.

Goal of Treatment: The goal of treatment of HCV-infected persons is to reduce all-cause mortality and liverrelated health adverse consequences, including end-stage liver disease and hepatocellular carcinoma by achieving virologic cure as evidenced by SVR.

\begin{tabular}{|c|c|}
\hline \multicolumn{2}{|c|}{ AASLD Recommendations for Chronic Hepatitis C } \\
\hline Geno-type & Recommendations \\
\hline Geno-type 1 & $\begin{array}{l}\text { A.Daclatasvir }(60 \mathrm{mg}) / \text { day plus sofosbuvir }(400 \mathrm{mg}) / \text { day for } 12 \text { weeks (No Cirrrhosis) or } 24 \text { weeks with or } \\
\text { without weight-based Ribavirin (Cirrhosis) } \\
\text { B.Ledipasvir ( } 90 \mathrm{mg} / \text { day) + sofosbuvir ( } 400 \mathrm{mg} / \mathrm{day}) \text { for } 12 \text { weeks } \\
\text { C. Simeprevir ( } 150 \mathrm{mg} / \text { day) plus sofosbuvir ( } 400 \mathrm{mg} / \text { day) for } 12 \text { weeks (No Cirrhosis) or } 24 \text { weeks with or without } \\
\text { weight-based Ribavirin(Cirrhosis) } \\
\text { D. Daily fixed-dose combination of paritaprevir }(150 \mathrm{mg}) / \text { ritonavir ( } 100 \mathrm{mg}) / \mathrm{ombitasvir}(25 \mathrm{mg}) \text { plus twice-daily } \\
\text { dosed dasabuvir ( } 250 \mathrm{mg} \text { ) with weight-based Ribavirin for } 12 \text { weeks (No Cirrhosis) or } 24 \text { weeks (Cirhhosis) }\end{array}$ \\
\hline Geno-type 2 & $\begin{array}{l}\text { A.Dailysofosbuvir }(400 \mathrm{mg}) \text { and weight-based Ribavirin for } 12 \text { weeks (No Cirhhosis) or 16-24weeks (Cirhhosis) } \\
\text { B.Dailydaclatasvir }(60 \mathrm{mg}) \text { plus sofosbuvir }(400 \mathrm{mg}) \text { for } 12 \text { weeks(No Cirhhosis) or 16-24weeks (Cirhhosis) } \\
\text { [Not eligible to receive RBV]. }\end{array}$ \\
\hline Geno-type 3 & $\begin{array}{l}\text { A.Daclatasvir }(60 \mathrm{mg}) / \text { day plus sofosbuvir }(400 \mathrm{mg}) / \text { day for } 12 \text { weeks (No Cirrrhosis) or } 24 \text { weeks with or } \\
\text { without weight-based Ribavirin (Cirrhosis } \\
\text { B.Sofosbuvir + ribavirin+PeEG INF for } 12 \text { weeks } \\
\text { C. Sofosbuvir + ribavirin for } 24 \text { weeks }\end{array}$ \\
\hline Geno-type 4 & $\begin{array}{l}\text { A.Daily fixed-dose combination of paritaprevir }(150 \mathrm{mg}) / \text { ritonavir }(100 \mathrm{mg}) / \mathrm{ombitasvir}(25 \mathrm{mg}) \text { and weight-based } \\
\text { RBV for } 12 \text { weeks(No cirhhosis/ Cirhhosis) } \\
\text { B. Daily fixed-dose combination of elbasvir }(50 \mathrm{mg}) / \mathrm{grazoprevir}(100 \mathrm{mg}) \text { for } 12 \text { (No cirhhosis/ Cirhhosis) } \\
\text { C.Daily fixed-dose combination of ledipasvir }(90 \mathrm{mg}) / \mathrm{sofosbuvir}(400 \mathrm{mg}) \text { for } 12 \text { weeks (No cirhhosis/ Cirhhosis) }\end{array}$ \\
\hline Geno-type 5/6 & $\begin{array}{l}\text { A. Daily fixed-dose combination of ledipasvir }(90 \mathrm{mg}) / \text { sofosbuvir }(400 \mathrm{mg}) \text { for } 12 \text { weeks (No cirhhosis/ Cirhhosis) } \\
\text { B. Daily fixed-dose combination of ledipasvir }(90 \mathrm{mg}) / \mathrm{sofosbuvir}(400 \mathrm{mg}) \text { for } 12 \text { weeks (No cirhhosis/ Cirhhosis) }\end{array}$ \\
\hline
\end{tabular}

\section{Recommendations for Management of Acute HCV Infection:}

HCV antibody and HCV RNA testing are recommended when acute HCV infection is suspected due to exposure, clinical presentation, or elevated aminotransferase levels. Regular laboratory and HCV RNA monitoring (every 4 weeks to 8 weeks) for 6 months to 12 months is recommended to determine spontaneous clearance of HCV infection versus persistence of infection.Patients with acute HCV infection are counselled to avoid hepatotoxic insults, including hepatotoxic drugs (eg, acetaminophen) and alcohol consumption, and to reduce the risk of $\mathrm{HCV}$ transmission to others.Before initiating treatment during the acute infection period, monitoring HCV RNA for at least 12 weeks to 16 weeks before starting treatment is recommended to allow for spontaneous clearance. Due to high efficacy and safety, the same regimens for acute infections are same as that are recommended for chronic HCV infection. Preexposure or postexposure prophylaxis with antiviral therapy or treatment of patients in whom HCV infection spontaneously clears is not recommended.

\section{Specific Population: Patients with Decompensated Cirrhosis}

Daily fixed-dose combination ledipasvir $(90 \mathrm{mg}) /$ sofosbuvir $(400 \mathrm{mg})$ with low initial dose of RBV (600 mg, increased as tolerated) for 12 weeks Or Daily daclatasvir $(60 \mathrm{mg})$ plus sofosbuvir $(400 \mathrm{mg}) \mathrm{with}$ low initial dose of RBV (600 mg, increased as tolerated) for 12 weeks 


\section{Specific Population: Patients with Renal Impairment}

A. In patients with mild to moderate renal impairment $(\mathrm{CrCl} 30 \mathrm{~mL} / \mathrm{min}-80 \mathrm{~mL} / \mathrm{min})$, no dosage adjustment is required when using daclatasvir, fixed-dose combination of ledipasvir $(90 \mathrm{mg}) / \mathrm{sofosbuvir}$ (400 $\mathrm{mg}$ ), or fixed-dose combination of paritaprevir $(150 \mathrm{mg}) /$ ritonavir $(100 \mathrm{mg}) / \mathrm{ombitasvir}(25 \mathrm{mg})$ with (or without for HCV genotype 4 infection) twice-daily dosed dasabuvir $(250 \mathrm{mg})$, simeprevir, or sofosbuvir

B.In patients with severe renal impairment $(\mathrm{CrCl}$ below30 $\mathrm{mL} / \mathrm{min})$

1. forgenotype $1 \mathrm{a}$, or $1 \mathrm{~b}$, or 4 infections:daily fixed-dose combination of elbasvir (50 $\mathrm{mg}) / \mathrm{grazoprevir}$ (100mg) for 12 weeks

2. for genotype $1 \mathrm{~b}$ infection: daily fixed-dose combination of paritaprevir (150 mg)/ritonavir (100 $\mathrm{mg}) / \mathrm{ombitasvir}(25 \mathrm{mg}$ ) plus twice-daily dosed dasabuvir $(250 \mathrm{mg})$ for 12 weeks

3. forgenotype 2, 3, 5, or 6 infection: PEG-IFN and dose-adjusted RBVat $200 \mathrm{mg}$ daily is a Recommended

\section{Prevention}

So far, there is no vaccine against the hepatitis $\mathrm{C}$ virus. To avoid the spread of the disease, following steps are recommended:

- To cover cuts and scratches with appropriate dressings.

- To dispose of blood stained items such as bandages and sanitary napkins hygienically.

- To avoid sharing personal items, that may have come in contact with an infected person's blood, even in amounts too small to see (such as toothbrushes and razors).

- To avoid sharing drug injecting equipment.

- To avoid tattooing, acupuncture or ear piercing where the equipment is not adequately sterilized.

- Safe sex practice.

- People with the hepatitis $\mathrm{C}$ virus should inform their health care professionals about virus carrier status.

\section{Conclusion}

HCV remains the major cause of cirrhosis of liver and hepatocellular carcinoma. Some patients lead to progression of liver disease despite of virological cure. Thus, it is most important to take appropriate steps for prevention of this deadly infection and early treatment with effective anti viral drug regimen. Hepatitis $C$ prevention activities must be accessible in both the public as well as private sectors. The most effective means to prevent $\mathrm{HCV}$ infection is to integrate hepatitis $\mathrm{C}$ prevention activities into existing clinical services and public health programs. Effective implementation of Hepatitis C Prevention Strategy would reduce the number of new $\mathrm{HCV}$ infections, and prevent the increase in chronic liver disease due to hepatitis $\mathrm{C}$.

\section{References}

[1]. Lavanchy D. The global burden of hepatitis C. Liver Int. 2009; 29:74-81

[2]. API Medicine Text book

[3]. Westbrook RH, Dusheiko G. Natural history of hepatitis C. J Hepatol. 2014; 61 (1 suppl); S58-68

[4]. Gurpreet S Wander, KK Pareek: Physician's role in eradicating hepatitis C. Chapter 240:Medicine update 2016-1, volume 26/2016: 1224-32 